\title{
Gado Bravo - PB: uma análise da degradação ambiental
}

\author{
Gado Bravo - PB: an analysis of environmental degradation \\ Gado Bravo - PB: un análisis de la degradación ambiental
}

\section{Resumo}

Com o avanço da degradação ambiental, no agreste paraibano, foi objetivado o estudo na zona rural do município de Gado Bravo, localizado na mesorregião do Agreste Paraibano. Realizando um estudo espaço-temporal da degradação ambiental da região, georreferenciando os poços artesianos contidos no município. No decorrer do estudo utilizamos técnicas de Processamento Digital das Imagens a partir das imagens obtidas pelos satélites Landsat 5 e 8 . Constatamos com o presente estudo que a região possui baixos níveis de degradação ambiental, apresentando ainda em determinadas regiões, devido a diminuição da exploração agrícola regional, a regeneração de algumas áreas. Tratando da água subterrânea, ela apresenta grande relevância social e econômica, pois movimenta toda a economia do município.

Palavras-chave: Água subterrânea; Agricultura; Georreferenciamento.

\begin{abstract}
With the advance of environmental degradation in the agreste region of Paraíba, the objective was to study the rural area of the municipality of Gado Bravo, located in the mesoregion of Agreste Paraíba. Carrying out a spatiotemporal study of the region's environmental degradation, georeferencing the artesian wells contained in the municipality. During the study, we used Digital Image Processing techniques from the images obtained by the Landsat 5 and 8 satellites. We found with this study that the region has low levels of environmental degradation, even showing in certain regions, due to the decrease in agricultural exploitation regional, the regeneration of some areas. Dealing with underground water, it has great social and economic relevance, as it moves the entire economy of the municipality.

Keywords: Ground water; Agriculture; Georeferencing.
\end{abstract}




\begin{abstract}
Resumen
Con el avance de la degradación ambiental en la región agreste de Paraíba, el objetivo fue estudiar el área rural del municipio de Gado Bravo, ubicado en la mesorregión de Agreste Paraíba. Realización de un estudio espacio-temporal de la degradación ambiental de la región, georreferenciando los pozos artesianos contenidos en el municipio. Durante el estudio, utilizamos técnicas de Procesamiento Digital de Imágenes a partir de las imágenes obtenidas por los satélites Landsat 5 y 8. Con este estudio encontramos que la región tiene bajos niveles de degradación ambiental, incluso mostrándose en ciertas regiones, debido a la disminución de la explotación agrícola. regional, la regeneración de algunas áreas. Al tratarse de aguas subterráneas, tiene una gran relevancia social y económica, ya que mueve toda la economía del municipio.
\end{abstract}

Palabras clave: Agua subterrânea; Agricultura; Georreferenciación.

\title{
1. Introdução
}

A degradação ambiental é um termo usado para qualificar os processos resultantes dos danos causados ao meio ambiente e pelos quais se perdem ou se reduzem algumas de suas propriedades. Geralmente está relacionada a uma série de fatores intrínsecos, entre os quais se podem citar a ação antrópica, o mau uso da terra, os baixos índices pluviométricos, as altas taxas de evaporação.

A definição do termo degradação ambiental consta na Lei no. 6.938 de 31 de agosto de 1981 (BRASIL, 1981), que institui a Política Nacional de Meio Ambiente e, no artigo 3, inciso II, assim o define: “degradação da qualidade ambiental, a alteração adversa das características do meio ambiente.” Assim, o decreto no. 97.632, de 10 de abril de 1989, dispõe sobre a regulamentação do art. $2^{\circ}$., inciso VIII, da Lei no. 6.938, que considera: “degradação os processos resultantes dos danos ao meio ambiente, pelos quais se perdem ou se reduzem algumas de suas propriedades, tais como a qualidade ou capacidade produtiva dos recursos ambientais" (BRASIL, 1989).

Os efeitos da degradação do solo, da poluição das águas e de muitos outros tipos de danos ambientais, assim como o aumento da consciência, na população, da sua dependência no que diz respeito ao meio ambiente em relação aos recursos naturais e à qualidade de vida, levaram a sociedade a despertar para o problema e a buscar soluções no curto, médio e longo prazo (Veneziani,1992; Attanasio, 2006). Assim, surgiram estudos relacionados aos impactos ambientais, associados às mudanças ocorridas no ambiente natural, ainda de forma incompleta, deixando de lado alterações de cunho social, alterações na qualidade de vida das populações humanas ou alterações no ambiente construído (Sánches, 1998; Queiroz, 2007). Guedes Filho et al. (2012) apontam os efeitos negativos dos impactos ambientais ocasionados pela ação humana no açude Bodocongó.

Costa (2011) afirma que os fatores que têm significativa contribuição ao processo de degradação ambiental do açude Bodocongó caracterizam-se pela ausência de rede coletora de esgoto e a presença de resíduos sólidos acumulados, gerando a proliferação de agentes etiológicos causadores de doenças transmissíveis, também, corroborando com Medeiros et al. (2012) indica que as atividades antrópicas aliadas à falta de consciência por parte da população e ainda, a ausência de fiscalização e a omissão dos poderes públicos são indicadores que aumentam a degradação do açude Bodocongó.

Desta forma, a recuperação de áreas degradadas pressupõe o conhecimento espacial e temporal, o que requer a contribuição de vários campos técnico-científicos que lidam com a questão ambiental. Diante da crescente degradação, os ecossistemas aquáticos acabam servindo como depósitos de uma grande variedade e quantidade de poluentes lançados no ar, no solo ou diretamente nos corpos d'água. Assim, a poluição do ambiente aquático, provocada pelo homem, direta ou indiretamente, produz efeitos deletérios, tais como: prejuízo aos seres vivos, perigo à saúde humana, efeitos negativos às atividades aquáticas (pesca, lazer, etc.) e prejuízo à qualidade da água com respeito ao uso na agricultura, indústria e outras atividades econômicas (Meybeck \& Helmer, 1996; Carvalho, 2007).

Assis (2015) diz que os crescentes processos de degradação dos solos, advindos de causas naturais como os fatores climatológicos e o relevo, tornam-se cada vez mais intensificados pelas ações antrópicas, tais como: desmatamento, 
queimadas, retirada da vegetação natural para implantação de agricultura, sobreutilização do solo, dentre outros, o que tem gerado discussões deste tema em âmbito mundial, tanto sob o ponto de vista político como também técnico-científico.

Toda água que após a precipitação, consegue infiltrar no solo, percola ou atravessa o interior do subsolo, ficando disponível para exploração através de sistemas de captação, é denominado de águas subterrâneas (Borghetti et al., 2004; AGA, 2015). A utilização dessa água possui maior evidência em regiões com déficit de chuvas, como o Nordeste brasileiro (Cirilo et al., 2007).

Durante a exploração da água subterrânea vários impactos ambientais são observados, alguns se dão, sobretudo através de poços tubulares, poços artesianos, essa exploração quando de forma adequada, não oferece grandes riscos ao meio ambiente (Vargas, 2002; IPCC, 2012).

As técnicas de geoprocessamento e sensoriamento remoto representam uma poderosa ferramenta computacional na busca de uma maior verificação da adequação do uso de recursos naturais (Amorim et al., 2017).

Segundo Andrade (2019), o monitoramento e mapeamento do uso da terra constitui um importante meio de contribuir para o planejamento territorial e subsidiar estratégias de gestão ambiental e manejo, afim de assegurar a conservação da biodiversidade e qualidade de vida da população.

Neste sentido, imagens de satélite vêm sendo amplamente utilizadas, pois fornecem dados que auxiliam na compreensão espacial e monitoramento da superfície terrestre. A utilização de ferramentas de sensoriamento remoto e geoprocessamento são essenciais no processo de extração de informações contidas em imagens orbitais, permitindo a identificação de mudanças naturais e/ou antrópicas no território ao longo do tempo (Florenzano, 2011).

O elemento essencial de um Sistema de Informação Geográfica (SIG) é o dado espacial ou geográfico. Em um SIG, todas as informações estão georreferenciadas, isto é, estão atreladas a um lugar no espaço (Ribeiro, 2018). Dessa forma, SIGs são, na atualidade, de suma importância para as questões de planejamento territorial envolvendo as mais diversas áreas do conhecimento, incluindo as ciências naturais, como geografia, geologia, biologia, arquitetura, engenharias; e as ciências da saúde (Hoffmann et al., 2018).

Diante do exposto, este trabalho tem como objetivo realizar o estudo espaço-temporal da degradação ambiental do município de Gado Bravo e georreferenciar os poços do município.

\section{Metodologia}

Os materiais utilizados foram: dados bibliográficos, produtos de sensores orbitais (imagens do TM/Landsat-5 e TM/Landsat-8), mapas temáticos, GPS (Global Positioning System) GarmimEtrexSummit para georreferenciar os alvos, câmera digital para o registro, e o suporte computacional físico (hadware) e lógico (software). O software utilizado foi o SPRING (Sistema para Processamento de Informação Georreferenciadas), versão 5.1.5, de domínio público, desenvolvido pela Divisão de Processamento de Imagem (DPI) do Instituto Nacional de Pesquisas Espaciais (INPE).

O município de Gado Bravo está localizado na mesorregião do Agreste Paraibano, entre as coordenadas geográficas

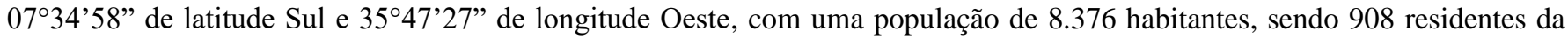
zona urbana e 7.468 residentes da zona rural (IBGE, 2014), (Figura 1). 
Figura 1. Localização do município de Gado Bravo.

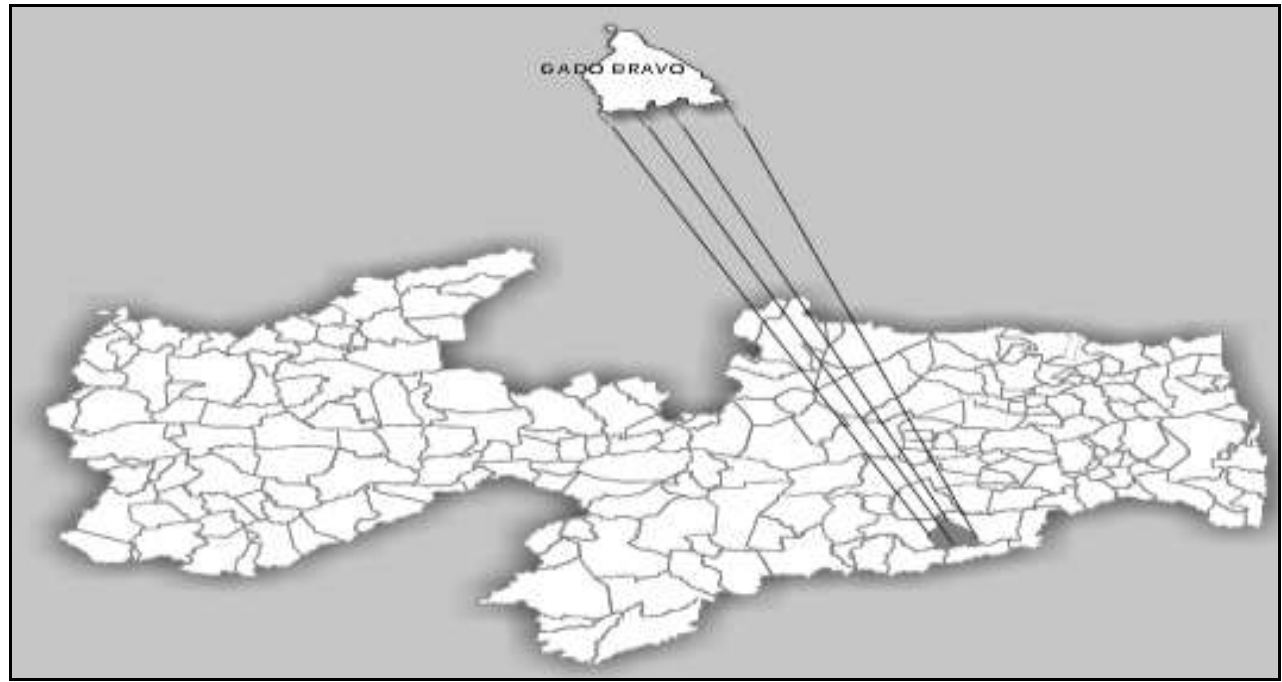

Fonte: CPRM (2005)

A ocorrência de água subterrânea se dá em fraturas e fendas, o que consiste em reservatórios pequenos, aleatórios e descontínuos, cujas águas em maior parte são salinizadas (CPRM, 2008; Medeiros, 2008).

Para realização do estudo espaço-temporal da degradação das terras foram utilizadas imagens obtidas pelos satélites Landsat 5, órbita 214, ponto 65 de 10 de julho de 1989 e Landsat 8, órbita 214, ponto 65 de 26 de abril de 2014.

O contraste entre dois objetos pode ser determinado como a razão entre os seus níveis de cinza médios, para manipular e tratar a imagem é feito uma transferência radiometria com ajuda de histogramas, objetivando obter o realce desejado (Câmara \& Medeiros, 1996).

O processo de segmentação classifica cada "pixel" como uma região distinta, em seguida realiza-se o cálculo de critério de similaridade para regiões adjacentes, este critério de similaridade fundamente-se em um teste de hipótese estatístico que testa a média obtida entre os alvos estudados, a imagem é dividida em um conjunto de subimagens e é realizada a união entre elas, de acordo com um limiar de agregação definido (Câmara \& Medeiros, 1996).

Após segmentar imagens, foi utilizado o classificador Battacharya, que classifica a região, medindo a separabilidade estatística analisando um par de classes espectrais, isto é, a realização de uma estimativa de uma média de probabilidade destas classes (Câmara \& Medeiros, 1996).

\section{Resultados e Discussão}

Foram gerados mapas, a partir das imagens dos satélites Landsat 5 e 8, permitindo a comparação da degradação no município no intervalo de 25 anos (entre os anos de 1989 e 2014), além do georreferenciamento dos poços da região (Figura 2a e b). 
Figura 2. a) Análide da degradação territorial de Gado Bravo (1989) e georreferenciamento dos poços do município.

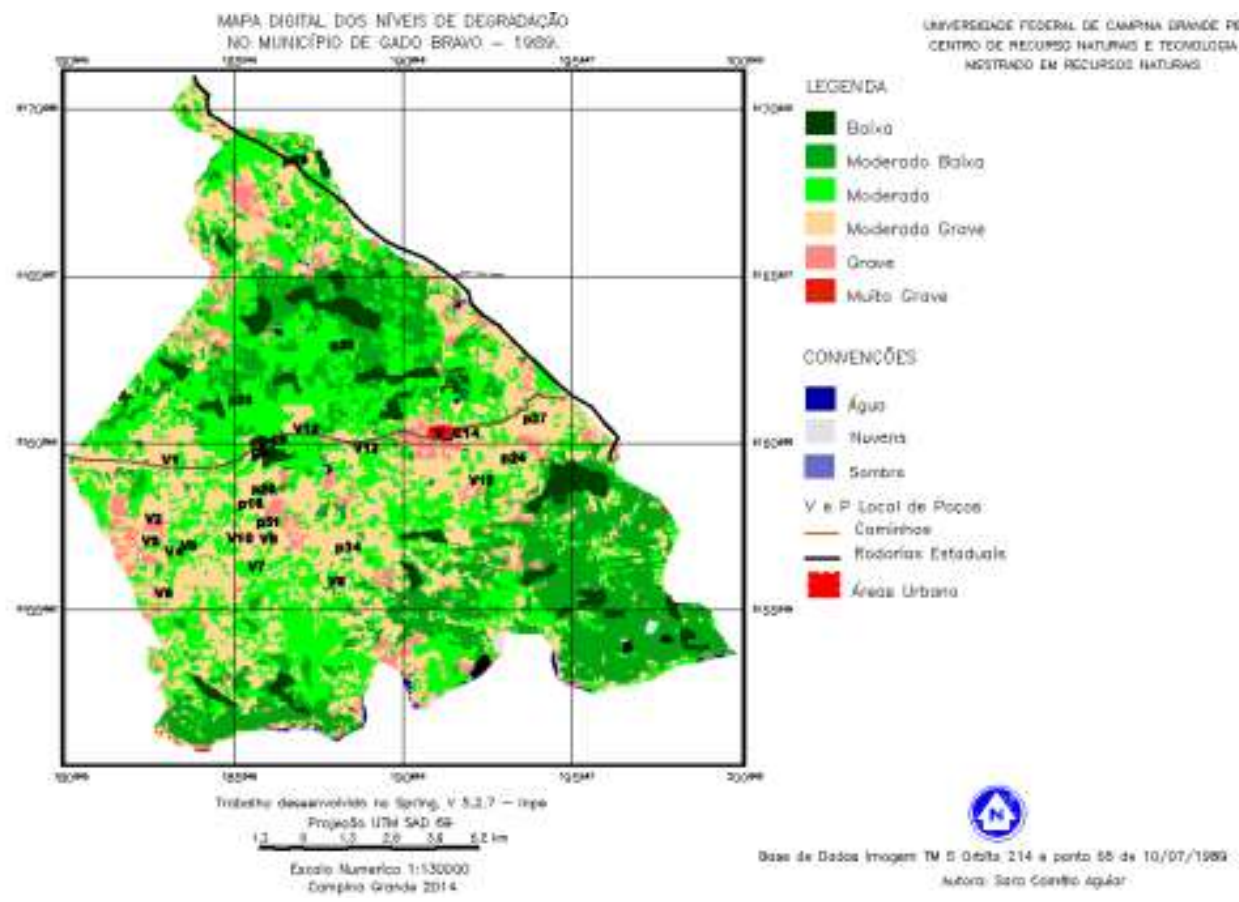

Fonte: Autores

O mapa de degradação para o ano de 1989 reflete uma extensa área de degradação na parte central do município, ao longo da principal estrada, representando bem a exploração agrícola e pecuária desenvolvida no município nas décadas de 80 e 90. A retirada da vegetação e a exploração agropecuária favoreceram assim os altos índices de degradação grave nessa região.

Figura 2. b) Degradação das terras de Gado Bravo para o ano de 2014 e georreferenciamento dos poços do município.

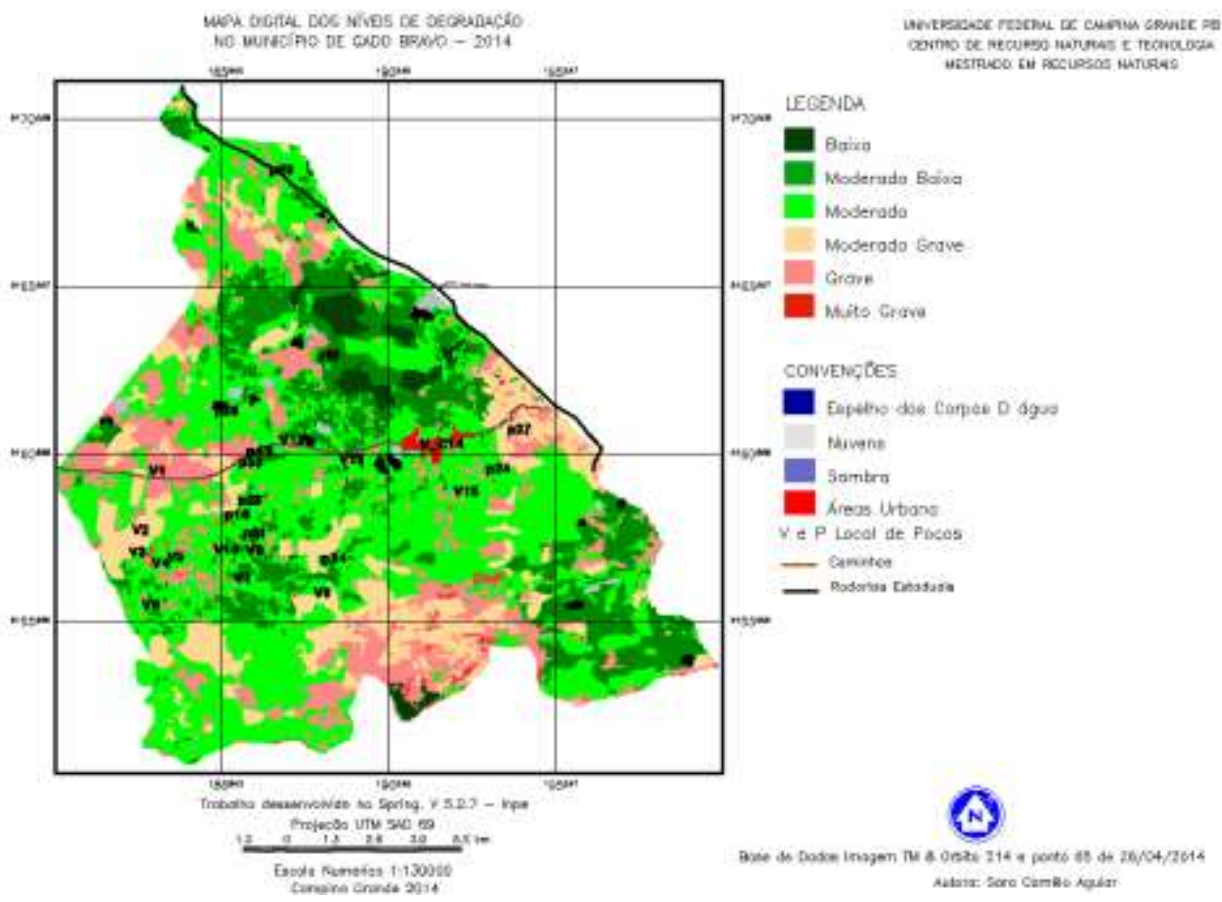

Fonte: Autores. 
Observa-se nos mapas de degradação um discreto aumento dos níveis de degradação baixo e moderado baixo, e uma pequena área de degradação muito grave, apesar do aumento percentual de 0,2\% para 1,8\% parecer grande como observado na Figura 3, isso representa uma área bem pequena quando comparado ao território do município. Em compensação as áreas relativas à degradação grave reduziram significativamente de 33,3 para apenas 10,4\%, o que denota uma regeneração expressiva daquelas áreas anteriormente exploradas com agricultura de sequeiro e pecuária extensiva. Um fator preponderante para recuperação dessas áreas é o abandono das atividades agropecuárias, possibilitando assim a regeneração. É importante observar que essa regeneração não se dá em algumas dessas áreas abandonadas.

Pode-se observar um acréscimo entre os anos de 1989 e 2014 de aproximadamente 100\% da degradação moderada grave, passando de 30,2\% em 1989, para 62,8\% em 2014, conforme visualizamos na Figura 3. Configurando assim, a derrubada da vegetação de maior porte para a areas voltas a podução de ração bovina, palma forrageira, milho e sorgo.

Figura 3. Evolução da degradação territorial de Gado Bravo no período (1989-2014).

\section{Degradação}

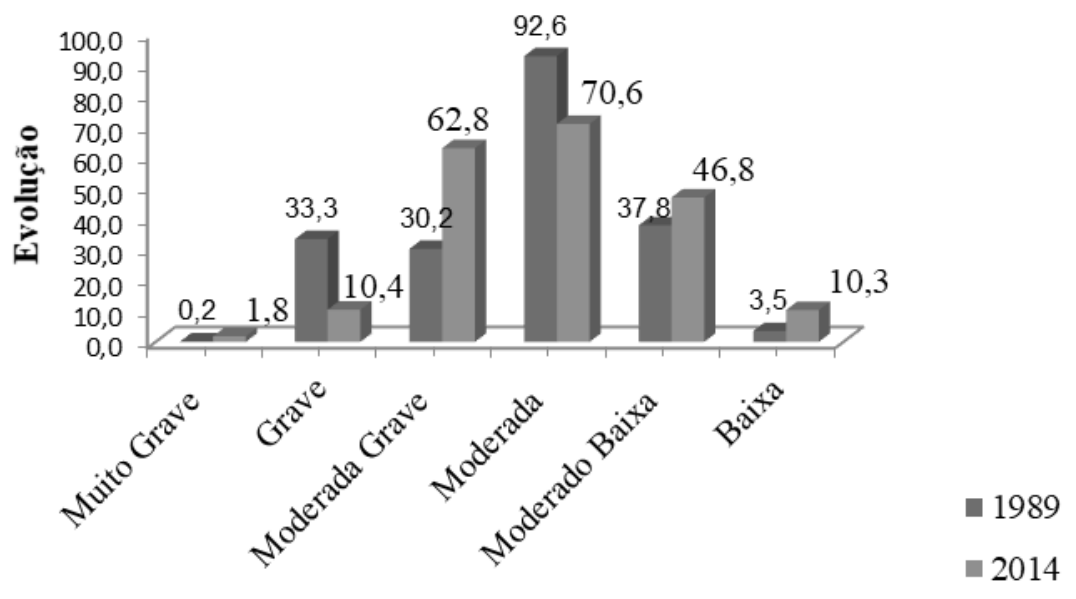

Fonte: Autores.

Porém, com relação à área mais central do município, onde está concentrado o maior número de poços georreferenciados no trabalho de campo, e que possui maior densidade demográfica; certamente devido à localização da principal estrada que corta o município, pode-se observar que corresponde a área que mais se regenerou, passando na maioria de moderado grave para moderado, fato que se deve a redução da agricultura em função da diminuição da regularidade das chuvas nos últimos 25 anos.

\section{Conclusão}

Concluímos com o estudo que o município se encontra com baixos níveis de degradação.

Algumas áreas analisadas apresentam regeneração em função da diminuição da prática da agricultura e da intensificação do plantio da palma forrageira consorciado com milho e sorgo.

As maiores variações de degradação ambiental ao longo dos 25 anos estudados foram para as classes de degradação muito grave que passou de $0,2 \%$ para $1,8 \%$ e moderado grave que passou de $30,2 \%$ para $62,8 \%$.

Houve um aumento significativo nos índices de degradação moderado baixo que passou de 37,8\% para 46,8\%, e baixo que passou de 3,5\% para 10,3\%, o que representa uma melhora dos níveis de degradação. 
Sugerimos ainda estudos para as mais diversas regiões, visando fomentar o banco de dados sobre o avanço da degradação ambiental em nosso país.

\section{Referências}

Amorim, J. V. A.; Frota, J. C. O.; Valladares, G. S.; Cabral, L. J. R. S.; Guimarães, C. C. B.; Coelho, R. M.; \& Aquino, R. P., (2017). Adequabilidade do uso agrícola das terras do sertão central do Ceará. Revista Brasileira de Geografia Física [online] 10. Disponível: https://doi.org/10.5935/1984-2295.20170012. Acesso: 19 jul. 2021.

Andrade, B. S.; Silva-Melo, M. R.; \& Da Silva, M. H. S. (2019). Geoprocessamento aplicado a análise do uso do solo na Área de Proteção Ambiental dos mananciais do Córrego Lajeado, Campo Grande - MS. Sociedade e Território, Natal, v. 31, p. 200-221, 2019.

ASSIS, F. R. V. de. (2015). Identificação de áreas potenciais à vulnerabilidade ambiental na microbacia do Talhado, Santa Luzia - PB. Dissertação de Mestrado em Ciências Florestais. CSTR/UFCG, Patos - PB. 2015. 105p.

Associação Guardiã Das Águas - AGA (2004). Água Subterrânea. <http://www.agua.bio.br/botao_d_H.htm>.

Attanasio, C. M.; Rodrigues, R. R.; Gandolfi, S.; \& Nave, A. G. (2006). Adequação ambiental de propriedades rurais recuperação de áreas degradadas restauração de matas ciliares. Universidade de São Paulo. Piracicaba. Julho 2006.

Brasil. Lei n 6.938, de 31 de agosto de 1981. Dispõe sobre a Política Nacional do Meio Ambiente, seus fins e mecanismos de formulação e aplicação, e dá outras providências. Diário Oficial da União, Brasília, 02 set. 1981.

Brasil. Decreto n. 97.632 de 10 de abril de 1989. Dispõe sobre a regulamentação do Artigo 2º inciso VIII, da Lei n. 6.938, de 31 de agosto de 1981, e dá outras providências. Diário Oficial da União, Brasília, 12 de abril de 1989.

Borghetti, N. R. B; et al. (2004). Aquífero Guarani: A verdadeira Integração dos Países do Mercosul. Ed. dos Autores. Curitiba, 2004.

Câmara G.; \& Medeiros, J. S. (1996). Geoprocessamento para projetos ambientais. Relatório do INPE. São José dos Campos: INPE.

Carvalho, A. P. (2007). Diagnóstico da degradação ambiental do açude de Bodocongó em Campina Grande - PB. Dissertação (Mestrado em Engenharia Agrícola). 96p. Centro de Tecnologia e Recursos Naturais, Universidade Federal de Campina Grande. Campina Grande.

Cirilo, J. A; et al. (2007). A questão da água no semiárido brasileiro. Disponível em: <www.abc.org.br/IMG/pdf/doc-811.pdf>.

Companhia De Pesquisa De Recursos Minerais - CPRM. (1998). Noções básicas sobre poços tubulares. Disponível em: <www.cprm.gov.br/pdf/deihd/manubt.pdf>.

Costa, T. C. F. (2011). Ações antrópicas de impactos negativos no Açude de Bodocongó no município de Campina Grande - Paraíba. Revista Brasileira de Informações Científicas. 2(2), 78-89. 2011. ISSN 2179-4413

Florenzano, T. G. (2011). Iniciação em sensoriamento remoto. (3 ed.). Oficina de Textos.

Guedes Filho, D. H.; Neto, S. F.; Santos Júnior, J. A.; Suassuna, J. F. \& Baracuhy, J. G. De V. (2012). Uso e ocupação nas margens do açude Bodocongó/PB. Revista Educação Agrícola Superior. Associação Brasileira de Educação Agrícola Superior - ABEAS - 27(1), 70-75. ISSN - 0101-756X - DOI: http://dx.doi.org/10.12722/0101-756X.v27n01a12.

Hoffmann, G. P.; Blank, M. M.; Amaral, L. C. M.; Nanni, A. S.; \& Osako, L. S. (2018). Adequação do software livre de Sistema de Informações Geográficas QGIS ao público brasileiro. Extensio: Revista Eletrônica de Extensão, Florianópolis, 15(31), 144-153. DOI: https://doi.org/10.5007/1807$0221.2018 \mathrm{v} 15 \mathrm{n} 31 \mathrm{p} 144$

Intergovernmental Panel on Climate Change - IPCC. (2012). Managing the Risks of Extreme Events and Disasters to Advance Climate Change Adaptation. Chapter 1: Climate Change: New Dimensions on Disaster Risk, Exposure, Vulnerability and Resilience. Cambridge University Press - Usa.

Medeiros, V C. de (Org.) et al. (2008). Geologia e Recursos Minerais da Folha Sousa SB.24-X-A. Serviço Geológico do Brasil. Recife: CPRM.

Medeiros, M. C. S.; Silva, J. A. L. Da.; \& Freitas, J. P. de. (2012). Diagnóstico das vulnerabilidades do açude de Bodocongó a partir da percepção dos atores sociais. Revista POLÊM!CA; 11(4), 717-724.

Paraíba. (2014). Agência Executiva de Gestão das Águas do Estado da Paraíba - AESA. Climatologias. Dsponível em: <www.aesa.pb.gov.br>.

Paraíba. (2014). Empresa de Assistência Técnica e Extensão Rural - EMATER. As origens da Extensão Rural. Disponível em: $<$ http://www.emater.pb.gov.br/>.

Queiroz, J. E. R.; Costa, I. C.; Oliveira, P. R. S.; Guimarães, C. L.; \& Silva, M. C. (2002). Batimetria apoiada por GPS - Relatório Técnico - Secretaria Extraordinária do Meio Ambiente. dos Recursos Hídricos e Minerais - Campina Grande.

Ribeiro, J. dos S. (2018). O uso do Sistema de Informação Geográfica (SIG) nas pesquisas de Administração. Trabalho de Conclusão de Curso. Universidade Federal De Uberlândia, Graduação em Engenharia Ambiental.

Sanchez, L. E. (1998). Conceitos de impacto e a avaliação de impacto ambiental: Definições diversas segundo diferentes grupos profissionais. VII Encontro Anual da Seção Brasileira da IAIA. Rio de Janeiro. 
Research, Society and Development, v. 10, n. 12, e383101220664, 2021

(CC BY 4.0) | ISSN 2525-3409 | DOI: http://dx.doi.org/10.33448/rsd-v10i12.20664

Vargas, J. E. (2002). Políticas públicas para lar educción de la vulnerabilidade frente a los desastres naturales y socio-naturales. Publicacion de Nacion Unidas (CEPAL). Santiago.

VenezianI, P. \& Anjos, C. E. dos. (1992). Metodologia de interpretação de dados de sensoriamento remoto e aplicações em geologia. INPE. São José dos Campos, 61p. 